\title{
The Tasmanian Epilepsy Register - A Community-Based Cohort
}

\author{
Background and Methodology for Patient Recruitment from the Australian National \\ Prescription Database
}

\author{
Wendyl J. D'Souza ${ }^{a, b}$ Jayne L. Fryer ${ }^{a}$ Stephen J. Quinn ${ }^{a}$ Bruce V. Taylor ${ }^{d}$ \\ David M. Ficker ${ }^{f}$ Terence J. O’Brien ${ }^{c}$ Neil E. Pearce ${ }^{e}$ Mark J. Cook ${ }^{b}$ \\ ${ }^{a}$ Menzies Research Institute, University of Tasmania, Hobart, Tas., bepartment of Medicine, University of \\ Melbourne, St. Vincent's Hospital and 'Department of Medicine, University of Melbourne, Royal Melbourne \\ Hospital, Melbourne, Vic., Australia; ${ }^{d}$ Department of Medicine, Christchurch Clinical School of Medicine, \\ Christchurch and ${ }^{\mathrm{e} C e n t r e}$ for Public Health Research, Massey University Wellington Campus, Wellington, \\ New Zealand; ${ }^{f}$ Department of Neurology, University of Cincinnati Academic Health Center, Cincinnati, Ohio, USA
}

\section{Key Words}

Epidemiology $\cdot$ Epidemiologic methods $\cdot$ Epilepsy $\cdot$ Patient recruitment $\cdot$ Prescriptions $\cdot$ Recruitment, neurology

\begin{abstract}
Background/Aims: Centralized prescription databases may provide an efficient mechanism for recruitment of community-treated disease. Methods: The Australian federal government agency, the Health Insurance Commission (HIC), invited patients to participate in the Tasmanian Epilepsy Register (TER). Eligible patients included those who received at least one anticonvulsant above a 'reportable' price threshold between July 1, 2001 and June 30, 2002. Patients were asked to disclose their medical indication for anticonvulsant treatment with additional demographic and prescription information obtained from the HIC. Results: 7,541 were eligible for recruitment. After two mail invitations over 6 months, 3,375 (46.6\%) had responded, but TER enrollment amongst those indicating treatment for epilepsy was 1,180 (78.3\%). TER participants were more likely to obtain their prescriptions exclusively from their general practitioner $(70.9 \%)$ or from combined sources $(19.1 \%)$ rather than from pediatrician
\end{abstract}

\section{KARGER \\ Fax +41613061234 \\ E-Mail karger@karger.ch}

www.karger.com
(C) 2008 S. Karger AG, Basel

0251-5350/07/0294-0255\$23.50/0

Accessible online at:

www.karger.com/ned
(4.2\%), neurologist (1.4\%) or general physician (1.0\%) sources. Patients were more likely to respond with increasing age (linear trend $p<0.001$ ), when from a higher socioeconomic area (linear trend $p<0.001$ ), or if their prescription was obtained from a neurologist $(p<0.001)$. Conclusion: The national Australian prescription database represents community-treated epilepsy and provides an effective and efficient method for patient recruitment for clinical epidemiological research.

Copyright $\odot 2008$ S. Karger AG, Basel

\section{Introduction}

Door-to-door household surveys have become the foundation for case ascertainment in epidemiological studies designed to measure the incidence or prevalence of epilepsy [1]. They were originally established for use in studies in developing countries, as part of a two-stage methodological design typically involving a screening questionnaire followed by diagnostic confirmation from a clinical neurological assessment $[2,3]$. This approach is considered necessary to comprehensively capture undi- 
agnosed and untreated disease, usually only seen outside a hospital setting, particularly in populations with inadequate access to specialist neurology services [4].

However, rigorous survey design requires considerable resources and is a relatively inefficient mechanism for generating sufficient cases when studying specific syndromes, etiological factors, or co-morbid conditions associated with epilepsy. The development of ascertainment methods primarily focused on effective and efficient case recruitment would be invaluable, particularly if the samples generated were representative of community-based disease [5].

The Australian Federal Parliament passed legislation in December 2000 enabling data to be linked from the national prescribed medicines database and an individual's national health information identifier. Our group was one of the first to utilize this relatively unique patient database for disease recruitment. In this paper, we describe the recruitment methodology used to establish a large community-based epilepsy cohort in the Australian island state of Tasmania and discuss its relative strengths and limitations.

\section{Methods}

\section{Geography and Population}

Tasmania is an island state situated off the southeastern tip of mainland Australia, comprising an area of $68,000 \mathrm{~km}^{2}$, with a population of 472,672 in 2002 [6]. The state is divided into the three main geographic and administrative regions comprising Southern $(231,662)$, Northern $(134,701)$ and Mersey-Lyell/NorthWestern $(106,309)$. The first European settlers arrived in 1804 , and by 1847 there were around 13,000 females in the total population of 70,000. Tasmania has attracted fewer immigrants than other Australian states, and it is estimated from genealogical records that in 6-7 generations approximately $65 \%$ of Tasmania's current population are direct descendants of these 13,000 female founders, many of whom were related. This makes Tasmania's population more genetically homogeneous than the populations of mainland states. This is supported by the Australian census, where $88.7 \%$ of Tasmanians indicated that both parents were of North Western European ancestry, compared, for example, to $69.4 \%$ of Australians from the state of Victoria [6]. Tasmania was chosen for this study as it has considerable benefits for conducting epidemiological research. Firstly, the state has significant goodwill towards medical research, leading to very high participation rates. Secondly, Tasmania's relatively stable migration patterns over the last 150 years mean that participants in longitudinal cohort studies (and studies dependent on family-based designs) are easily traced, as they remain resident within the state [7].

Medical Provider Services

In Australia, consultative and investigational health services are significantly funded by the federal government allowing uni- versal means independent access to health services. General practitioners and specialists can either charge only the federally-funded rebate amount [and claim it directly from the Health Insurance Commission (HIC)] or alternatively choose to charge above this amount, with the patient then paying the whole service fee to the doctor before claiming the rebate portion from a HIC Medicare rebate outlet. Consultations with public hospital specialists do not incur any fee directly to the patient. Patients can also be diagnosed and managed by a private specialist, but must be referred by a general practitioner, for this service to attract a federally funded specialist rebate [8]. In Tasmania, regional specialist physicians comprised: 6 pediatricians, 4 general physicians and 2 neurologists residing in the south; 3 pediatricians, 2 general physicians and 1 neurologist residing in the north, and 2 pediatricians and 3 general physicians residing in the north-west. In addition, 3 interstate epileptologists visit the south (2 bimonthly, 1 monthly) and 1 the north (every 3-4 months).

Pharmaceutical Benefits Scheme and the Australian National Prescription Database

National prescription data records are generated when the government contributes to the cost of a pharmaceutical product dispensed under the Australian Pharmaceutical Benefits Scheme (PBS) and Repatriation Pharmaceutical Benefits Scheme (RPBS). The PBS/RPBS is a subsidization program monitored by the HIC. Patients are classified into one of two categories, which determines the amount the patient contributes and the amount of subsidy paid by the government. General beneficiaries make a maximum patient contribution (AUD 22.40 in 2002) per prescription item; concessional beneficiaries (primarily social security recipients) or veteran affairs (returned servicemen and women) categories purchase drugs at a concession rate (AUD 3.60 in 2002). Additional 'safety net' arrangements limit the total annual contribution that a family can make towards prescription costs for each of these categories of patient. Once these limits are reached, any PBS/RPBS prescriptions dispensed, are either free or with a much reduced co-payment for the remainder of the safety net period [9].

These arrangements have implications on the PBS/RPBS data set. When a patient pays the entire cost of the medication, there is no HIC record of the prescription. Prescription records for drugs costing less than the general patient co-payment will not be complete (only recorded for concessional beneficiaries and those who have reached safety net entitlements). There will be complete capture for more expensive drugs, as the government will have made a contribution in every case [10].

Table 1 lists the PBS/RPBS anticonvulsant items selected. Only five of these anticonvulsants (phenobarbitone, phenytoin suspension, carbamazepine liquid, carbamazepine $50 \mathrm{mg}$ and lamotrigine $5 \mathrm{mg}$ ) cost less than AUD 22.40, and so had limited capture. Some anticonvulsant medications were not selected (topiramate sprinkles, levetiracetam, oxcarbamazepine, and pregabalin) because at the time they were not PBS/RPBS listed medications. Benzodiazepines and acetazolamide prescriptions were excluded from selection because they were more likely to be prescribed as single agents for other conditions.

At the end of 2000, Australian Federal Parliament passed the National Health Act Amendment - Improved Monitoring of Entitlement of Pharmaceutical Benefits. An important part of this legislation requires pharmacists in Australia to ask all consumers 
for their healthcare identification number (Medicare number or Veterans' Repatriation Health Card entitlement number) when they respectively present with a prescription for a PBS- or RPBSsubsidized medicine. This changed legislation meant that no government payment would be made to a pharmacist for a prescription unless an appropriate Medicare number was included with each claim. Pharmacists were required to record a Medicare number for each PBS or RPBS script in their pharmacy dispensing software and to include the number with each claim for payment from the HIC. Where a person did not have a Medicare card, the person would need to pay full (non-subsidized) price for the prescription and claim a reimbursement from the HIC on provision of their Medicare number, subject to a check of their eligibility by the HIC. Special numbers were also established to cover emergencies and other situations where consumers were eligible but could not produce a Medicare card. Until these legislation changes, prescriptions recorded by the HIC could not be attributed to individual patients. These changes also enabled non-identifying cross-matched prescription data to be obtained on age, gender, postcode region, date of dispensing, the category of recipient (general, concessional, doctors emergency bag, safety net, or veteran affairs) and category of prescriber.

\section{Recruitment of Participants}

The target sample frame involved all those persons who have been supplied at least one prescription for an anticonvulsant medication in Tasmania above the 'reportable' PBS/RPBS threshold during the 12-month period July 1, 2001 to June 30, 2002. To be eligible, participants must have a listed postcode in Tasmania when collecting their prescription during this period.

Under privacy legislation, the release of information concerning the affairs of a person receiving benefits under the PBS/RPBS is prohibited except in exceptional circumstances. This meant our study team could not have access to HIC-held names and addresses until those patients agreed to participate in the Register. Therefore, each HIC sample patient was given a unique identifying number to enable invitation and the tracking of response to be conducted anonymously from our study team. Patients were sent an information package explaining the reasons for approaching them, outlining the aims of the study and inviting them to enroll on the Register on November 20,2002. A second mail invitation was sent to those invited patients who had failed to respond within 3 months of our initial invitation (February 19, 2003), unless we had received a 'return to sender' notification or information that they had deceased. Those patients who did not respond to the second mail-out within 3 months of its dispatch were classified as non-responders. As anticonvulsant medications can be prescribed for other medical conditions, invited HIC patients were asked to disclose if they were prescribed their anticonvulsant for 'blank spells, seizures or epilepsy', so that their disease status could be recorded.

Once they had accepted an invitation, Register patients were contacted by telephone and written consent obtained after discussion with the study team. The telephone interviewing center was then given the names, telephone contact details and best times for contact so that the baseline interviews could be conducted. The HIC patients may refuse Register enrollment, or withdraw from participation after initially agreeing. They may indicate this to the study team or the HIC anonymously (from the study team) by mail or directly by telephone.

Tasmanian Epilepsy Register Recruitment
Table 1. 'Reportable' anticonvulsant medications* supplied in Tasmania between July 1, 2001 and June 30, 2002

\begin{tabular}{|c|c|}
\hline Generic name & Preparation \\
\hline Methylphenobarbitone & Tablet \\
\hline Phenobarbitone & Tablet ${ }^{\mathrm{a}}$ \\
\hline Primidone & Tablet \\
\hline Carbamazepine & Tablet $^{\mathrm{b}}$ \\
\hline Carbamazepine & Tablet (controlled release) \\
\hline Carbamazepine & Liquid $^{\text {a }}$ \\
\hline Gabapentin & Tablet \\
\hline Lamotrigine & Tablet $^{\mathrm{c}}$ \\
\hline Phenytoin & Suspension ${ }^{\mathrm{a}}$ \\
\hline Phenytoin & Tablet \\
\hline Phenytoin sodium & Tablet \\
\hline Sodium valproate & Tablet \\
\hline Sodium valproate & Tablet (enteric-coated) \\
\hline Sodium valproate & Liquid \\
\hline Sodium valproate & Syrup \\
\hline Topiramate & Tablet \\
\hline Topiramate & Sprinkles \\
\hline Ethosuximide & Tablet \\
\hline Sulthiame & Tablet \\
\hline Tiagibine & Tablet \\
\hline Vigabatrin & Tablet \\
\hline
\end{tabular}

* All the anticonvulsant medications retail at more than AUD 3.60 and there is a HIC record generated for all concession card patients receiving these drugs from a pharmacist. When medications retail at less than AUD 22.40 there is no HIC record generated for general patients receiving these drugs from a pharmacist.

${ }^{\text {a }}$ Incomplete capture; ${ }^{\mathrm{b}, \mathrm{c}}$ Incomplete capture only for 50 - and 5-mg preparations, respectively.

\section{Methods Used to Maximize Participation}

To maximize recruitment a promotional campaign was carried out prior to the HIC mail invitations. This involved presentations through established health professional and community organizations involved in the management and advocacy of epilepsy in the state. The organizations included the regional Divisions of General Practice, hospital general physicians, pediatricians, neurologists and the Epilepsy Association of Tasmania in the three main regional centers - Hobart, Launceston and Burnie. Presentations were also conducted with the three pharmacist representative organizations of the Pharmaceutical Guild of Tasmania, the Tasmanian Branch of the Pharmacist Society of Australia, and the Society of Hospital Pharmacists. A poster and information pamphlets were displayed and made available in prominent locations at all pharmacies, general practices, hospital neurology outpatient clinics and Epilepsy Association of Tasmania regional offices in the state. In addition, a media campaign was undertaken with a media release, a prime time news story on the Australian national television broadcaster, a news item and talkback session on the state radio station, media releases through 
the main state and regional newspapers and an item in each of the health professional and epilepsy association newsletter networks.

\section{Data Collection, Management and Storage}

The HIC had sole access and administration of national prescription data until eligible patients consented to participate in the Register. The names and addresses of participants consenting to be involved in the Register were saved and transferred to the center involved in conducting the baseline interviewing of participants involving diagnosis, risk factors, health service utilization, and co-morbid conditions (data not included). When all the baseline questionnaires were completed, a designated person maintained sole responsibility for collating, checking completeness of data entry, and storage of all data in preparation for analysis. Upon obtaining questionnaire data, at the interviewing center, all identifying information was removed from the medical data and questionnaires.

\section{Statistical Analysis}

Non-Responder Bias

Recruitment through the HIC allowed us to obtain non-identifying demographic and treatment information for HIC patients on age, gender, postcode region, socioeconomic status derived from postcode, prescribing doctor type and all other prescribed medications. To assess the representativeness of our responder sample, variations in our HIC mail invitation between responders versus non-responders were analyzed for these variables with a $\chi^{2}$ test for differences between proportions. A test for trend in the proportion responding across levels of the characteristic (age, socioeconomic status) was also conducted by fitting a univariable log binomial model and fitting the characteristic as a linear predictor.

\section{Socioeconomic Index for Area (SEIFA)}

Developed by the Australian Bureau of Statistics and using data derived from the 2001 Census of Population and Housing, the SEIFA 2001 provides a range of measures to rank geographic areas based on their relative social and economic wellbeing [11]. In 2001, there were four indexes, each summarizing a different aspect of the socioeconomic conditions in an area. This report utilizes the Index of Relative Socio-Economic Advantage/Disadvantage. This is derived from attributes such as low income, low educational attainment, high unemployment, jobs in relatively unskilled occupations and variables that reflect disadvantage rather than measure specific aspects (e.g., Indigenous and Separated/Divorced). High scores on the Index of Relative Socio-Economic Advantage/Disadvantage occur when the area has few families of low income and few people with little training and in unskilled occupations. In 2001, Tasmania was the most disadvantaged state with a fewer proportion of residents in the higher SEIFA quintiles compared to all other Australian states. Therefore, for this analysis, the SEIFA index values were partitioned into quintiles that were approximately equal in size across the Tasmanian population.

\section{Ethical Approvals}

Approval was obtained for the recruitment, baseline interviews, data storage and analysis from the Southern Tasmania Health and Medical Human Research Ethics Committee. Ap- proval was also obtained for recruitment through the HIC Medicare-PBS/RPBS database from the HIC Ethics Committee and the Department of Veterans' Affairs Human Research Ethics Committee. Participants were asked to sign an Informed Consent Statement to participate in the Register. This statement explained the nature and content of the Register, the nature of their participation, issues relating to confidentiality and privacy, and voluntary participation in potential future studies.

\section{Results}

\section{Patient Recruitment and Participation}

Figure 1 summarizes the recruitment process and patient participation onto the Tasmanian Epilepsy Register from the Australian National Prescription Database. A total of 7,737 persons received 'reportable' prescriptions for anticonvulsant medications in Tasmania between July 1, 2001 and June 30, 2002, of which 7,541 had a listed Tasmanian address and were sent an invitation letter from the HIC. However, we received information that 48 had deceased and 247 were no longer resident at the address listed with the HIC from the time of sampling through the recruitment process (June 30, 2002 to May $31,2003)$. Therefore, 7,246 were available to participate in the Register. Only 4.8\% (372/7,737) of the persons had received RPBS prescriptions. Data on the specific dispensed anticonvulsant and doctor provider type was missing from the HIC database in $6.2 \%(470 / 7,541)$ of persons for which all were 'general' patients without a 'safety net'. A total of 1,957 patients responded to mailout 1 and 1,418 responded to mailout 2 . The overall eligible mail invitation response rate was $44.8 \%(3,375 / 7,541)$. Following the 6 -month recruitment process, 1,180 were enrolled on the Tasmanian Epilepsy Register, giving an overall participation rate of $34.9 \%(1,180 / 3,375)$. However, only half of all respondents indicated they were taking anticonvulsants for epilepsy and the participation rate amongst this group was considerably higher at $78.3 \%$ $(1,180 / 1,507)$.

The 7,071 patients for which HIC data were available had records corresponding to 13,033 prescriptions (data not shown). The majority of anticonvulsant prescriptions $(82.4 \%, 10,734 / 13,033)$ from the HIC sample and enrolling on the Epilepsy Register $(82.1 \%, 2,354 / 2,866)$ had been obtained from a general practitioner. In the preceding 12 months, Register participants were more likely to obtain their prescriptions exclusively from their general practitioner (70.9\%) or from combined sources (19.1\%) rather than from other sources (table 2). 
Fig. 1. Summary of patient recruitment and participation onto the Tasmanian Epilepsy Register. * 'Reportable' anticonvulsant prescriptions: see table 1 for listed medications in 2002. PBS = Pharmaceutical Benefits Schedule, RPBS = Repatriation Benefits Schedule, HIC = Health Insurance Commission (Federal Government Agency that monitors healthcare entitlements including the Australian $\mathrm{Na}$ tional Prescription Database).

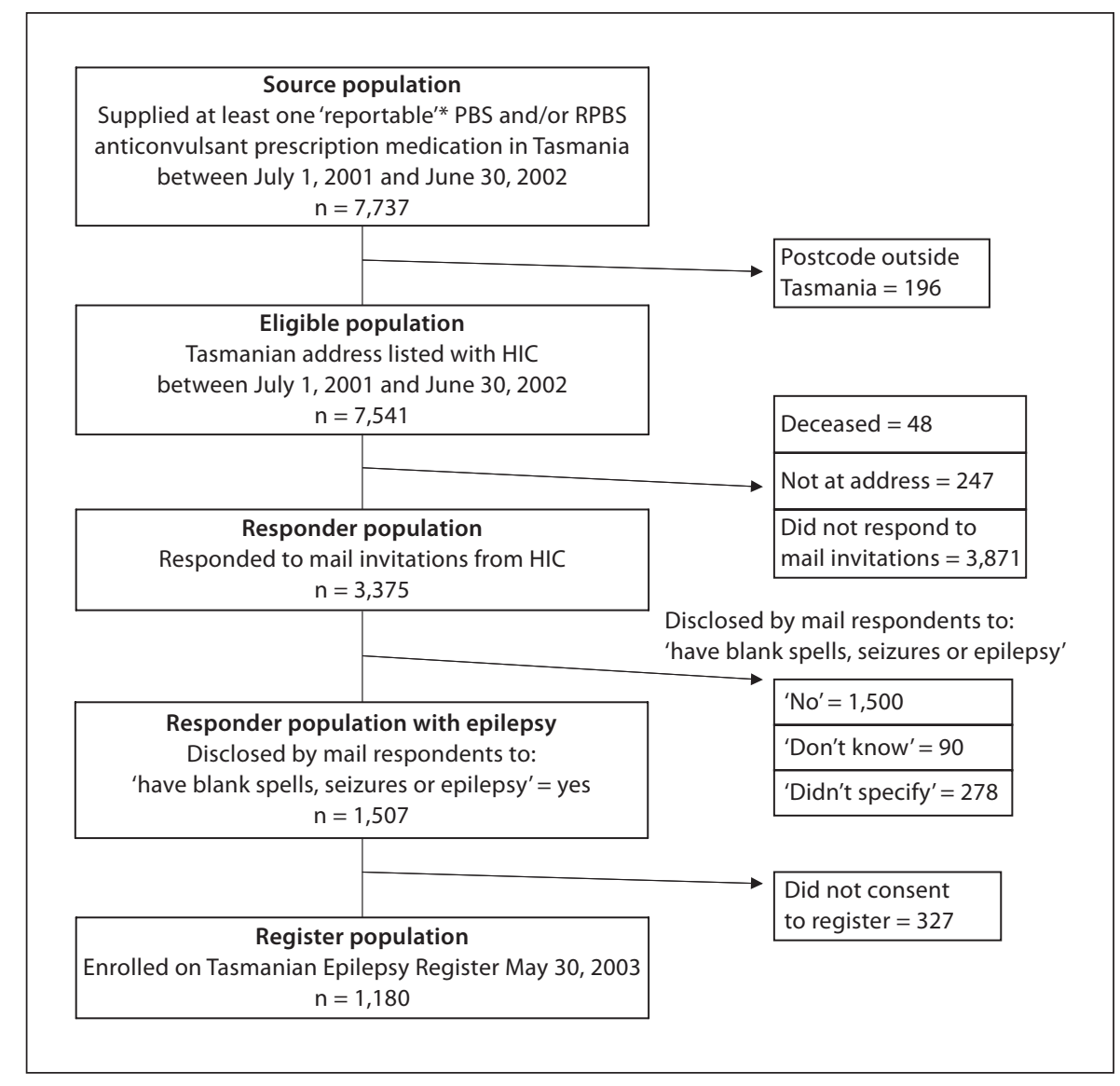

\section{Non-Responder Bias}

Table 3 shows the demographic features of the Tasmanian population, mail responders, non-responders and Epilepsy Register participants. Patients taking anticonvulsant were more likely to respond with increasing age (trend $\mathrm{p}<0.001$ ), or when from a higher socioeconomic quintile (linear trend $\mathrm{p}<0.001$ ) with over-representation if female almost reaching significance $(\mathrm{p}=0.053)$. In addition, patients taking anticonvulsants were more likely to respond to our invitation if their prescription was obtained from a neurologist and less likely to respond if their prescription was obtained from a psychiatrist $(\mathrm{p}=$ 0.007). No regional differences in response were found.

\section{Discussion}

The main aim of this study was to enroll a representative population cohort of community-treated epilepsy cases. This recruitment design is relevant for researchers in countries with centralized prescription databases in-
Table 2. Comparison of HIC sample versus Register participants for anticonvulsant provider type in Tasmania between July 1, 2001 and June 30, 2002

\begin{tabular}{lcrrrrr}
\hline \multirow{2}{*}{ Provider type } & \multicolumn{2}{l}{ HIC sample } & & \multicolumn{2}{l}{ Register } \\
\cline { 2 - 3 } & $(\mathrm{n}=7,541)$ & $\%$ & & $(\mathrm{n}=1,180)$ & $\%$ \\
\hline Surgical specialist & 91 & 1.2 & & 1 & 0.1 \\
General practitioner & 5,420 & 72.1 & & 837 & 70.9 \\
General physician & 186 & 2.6 & & 12 & 1.0 \\
Neurologist & 115 & 1.5 & 17 & 1.4 \\
Pediatrician & 162 & 2.3 & 49 & 4.2 \\
Psychiatrist & 254 & 3.5 & 6 & 0.5 \\
Combination & 843 & 10.7 & 225 & 19.1 \\
Not known & 470 & 6.1 & 33 & 2.8 \\
Total & 7,541 & 100.0 & & 1,180 & 100.0 \\
\hline
\end{tabular}

a Includes qualified medical practitioners not in specialty training. 
Table 3. Demographic features of the Tasmanian population, Register participants, responders and non-responders by age, gender, region and socioeconomic status

\begin{tabular}{|c|c|c|c|c|c|c|c|c|c|}
\hline & \multicolumn{2}{|l|}{ Tasmania } & \multicolumn{2}{|l|}{ Register } & \multicolumn{2}{|l|}{ Responder $^{\mathrm{a}}$} & \multicolumn{2}{|c|}{ Non-responder ${ }^{b}$} & \multirow{2}{*}{$\begin{array}{l}\text { Responder } \\
\text { vs. non- } \\
\text { responder } \\
\text { p value }\end{array}$} \\
\hline & $(\mathrm{n}=472,672)$ & $\%$ & $(\mathrm{n}=1,180)$ & $\%$ & $(\mathrm{n}=3,375)$ & $\%$ & $(\mathrm{n}=4,166)$ & $\%$ & \\
\hline \multicolumn{10}{|l|}{ Age } \\
\hline $0-9$ & 63,717 & 13.5 & 36 & 3.1 & 51 & 1.5 & 71 & 1.7 & \\
\hline $1-19$ & 68,096 & 14.4 & 113 & 9.6 & 172 & 5.0 & 233 & 5.7 & \\
\hline $20-29$ & 56,153 & 11.9 & 115 & 9.7 & 218 & 6.4 & 433 & 10.5 & \\
\hline $30-39$ & 64,730 & 13.7 & 136 & 11.5 & 327 & 9.6 & 623 & 15.1 & \\
\hline $40-49$ & 70,829 & 15.0 & 233 & 19.7 & 536 & 15.9 & 727 & 17.5 & \\
\hline $50-59$ & 60,386 & 12.8 & 256 & 21.7 & 688 & 20.4 & 681 & 16.3 & \\
\hline $60-69$ & 41,233 & 8.7 & 161 & 13.6 & 546 & 16.2 & 497 & 11.9 & \\
\hline $70-79$ & 30,747 & 6.5 & 95 & 8.1 & 490 & 14.5 & 445 & 10.7 & \\
\hline $80+$ & 16,781 & 3.6 & 35 & 3.0 & 347 & 10.3 & 456 & 10.9 & $<0.001^{\mathrm{c}}$ \\
\hline \multicolumn{10}{|l|}{ Gender } \\
\hline Female & 232,768 & 49.2 & 574 & 48.6 & 1,763 & 52.2 & 2,083 & 50.0 & \\
\hline Male & 239,904 & 50.8 & 606 & 51.4 & 1,612 & 47.8 & 2,083 & 50.0 & $0.053^{\mathrm{d}}$ \\
\hline \multicolumn{10}{|l|}{ Region } \\
\hline Mersey-Lyell & 106,309 & 22.5 & 274 & 23.2 & 753 & 22.3 & 965 & 23.2 & \\
\hline Northern & 134,701 & 28.5 & 322 & 27.3 & 871 & 25.8 & 1,024 & 24.6 & \\
\hline Southern & 231,662 & 49.0 & 584 & 49.5 & 1,751 & 51.9 & 2,177 & 52.3 & $0.414^{\mathrm{d}}$ \\
\hline \multicolumn{10}{|l|}{ SES } \\
\hline 1 - Low & 104,859 & 22.2 & 257 & 21.8 & 701 & 20.8 & 1,054 & 25.3 & \\
\hline 2 - Low/moderate & 92,058 & 19.4 & 233 & 19.7 & 701 & 20.8 & 884 & 21.2 & \\
\hline 3 - Medium & 91,397 & 19.3 & 234 & 19.8 & 605 & 17.9 & 714 & 17.2 & \\
\hline 4 - Moderate/high & 90,750 & 19.2 & 233 & 19.7 & 673 & 19.9 & 764 & 18.3 & \\
\hline 5 - High & 93,608 & 19.8 & 216 & 18.3 & 678 & 19.9 & 715 & 17.2 & \\
\hline Missing data & & & 7 & 0.6 & 25 & 0.7 & 35 & 0.8 & $<0.001^{\mathrm{c}}$ \\
\hline $\begin{array}{l}\text { a Responders includ } \\
{ }^{\mathrm{b}} \text { Non-responders ir } \\
{ }^{\mathrm{c}} \text { SES = Socioeconor } \\
{ }^{\mathrm{d}} \chi^{2} \text { test for trend. } \\
{ }^{\mathrm{e}} \chi^{2} \text { test for differen }\end{array}$ & $\begin{array}{l}180 \text { finally enro } \\
\text { de: } 48 \text { 'deceasec } \\
\text { index for area ( } \\
\text { etween propor }\end{array}$ & $\begin{array}{l}\text { led or } \\
\text { and and } \\
\text { EIFA }\end{array}$ & $\begin{array}{l}\text { gister. } \\
\text { 'not at addre } \\
\text { intile. } \\
\text {-sided). }\end{array}$ & & & & & & \\
\hline
\end{tabular}

tending to conduct studies with large sample sizes, e.g. when estimating the prevalence of epilepsy subtypes, comorbid conditions, syndrome-focused case-control studies, or longitudinal cohort studies. We deliberately set out not to extensively target patients receiving anticonvulsants from neurologists, pediatricians and general physicians, outside our mail recruitment campaign. This was to ensure our sample was not disproportionately enriched by hospital-treated cases, and to demonstrate the effectiveness and efficiency of this recruitment design, independent of doctor referral.

General practice and anticonvulsant prescription data for case ascertainment are often linked in studies of epilepsy prevalence $[12,13]$. This is not surprising considering that general practitioners are often the first point of contact, as well as the 'gatekeepers' for further access of health services, including prescriptions, and specialist referral $[14,15]$. The General Practice Research Database (GPRD) in the United Kingdom, originally established to prospectively track prescribing practice and adverse events, is probably the most analogous to our population cohort [16]. This database has provided important patient population morbidity studies in epilepsy as it provides a source of continuous data on the diagnosis and treatment of illness in general practice as all individuals registered can be traced efficiently [17]. Hence, our choice in recruitment using the Australian National Prescription Database was primarily because it was likely to reflect community-treated disease, but unlike the GPRD which hold anonymous records, allowed us to re-identify cases 
for longitudinal cohort studies by directly communicating with individuals and their families.

The HIC prescription database only includes persons subsidized through the PBS and RPBS scheme above a 'reportable' retail price. In February 2002, all the anticonvulsant medications had a retail price more than the 'safety net' or 'concessional' patient price threshold and only the infrequently prescribed barbiturate anticonvulsants and preparations for patients with swallowing difficulties and young children (typically $<8$ years of age) retailed below the 'general' patient price threshold. With less 'general' patients in Tasmania than other Australian states [11], and low-dose tablet preparations usually used in dose titration (rather than dose end-point), we expect the HIC sample frame is a comprehensive anticonvulsant treatment database for all 'concession' cardholders and, with maybe the exception of very young children on single liquid preparations, the majority of remaining 'general' patients.

We chose our sample period to coincide with the implementation of 'Improved Monitoring of Entitlements' legislative changes on July 1, 2001, that would enable our recruitment strategy through the HIC. Medication, demographic and doctor provider type information was complete on $94 \%(7,071 / 7,541)$ of the HIC prescription database during the time of our recruitment study, which compares favorably with the $90 \%$ accuracy of the GPRD [16]. As is commonly the case in mail surveys, we found older, and people from higher socioeconomic areas overrepresented among responders to our mail invitations [18].

Although more representative than specialist sources, epilepsy diagnosis statistics generated from general practice are less likely to be accurate without prior referral for specialist assessment, with general practitioners reporting diagnostic uncertainty especially in neurological disease [15]. Hence, health systems with high referral practice and early access to specialist services are likely to have less diagnostic false positives and false negatives in epidemiological research, when sampling is from general practice sources. Studies have consistently suggested high access to tertiary health services in the United Kingdom $[17,19]$, with $76.2 \%$ of persons seen at some time by a neurologist or pediatrician, $15.6 \%$ seen by another hospital specialist and in only $8.2 \%$ was hospital referral not undertaken [17]. However, half of these referred patients attend mainly for a short early diagnostic period and are subsequently managed by their general practitioner. Therefore, although only $20.5 \%$ of our Register cohort is currently partly or exclusively managed by a medical spe-

Tasmanian Epilepsy Register

Recruitment cialist, it is conceivable that the pattern of high tertiary access at initial diagnosis found in other developed countries $[20,21]$ may also be present in Tasmania.

We acknowledge that anticonvulsant treatment may not be universal for patients who have a diagnosis of epilepsy, particularly in developing countries where fewer patients are on regular treatment $[22,23]$. However, in a number of communities, anticonvulsant medications have been demonstrated to have widespread use and penetration in treating epilepsy $[24,25]$. Every person identified as having epilepsy in a door-to-door community survey in Australia had been prescribed anticonvulsant medications at some time in their lifetime, with virtually all of the one-third 'off medication on survey day' seizure-free in the preceding year [26]. Although this level of treatment uptake for clinically active disease is unlikely to be universal [27], particularly in some ethnic groups [28], high lifetime access to anticonvulsant treatment for epilepsy, has also been demonstrated in a number of other communities [29-31], suggesting these circumstances are not unique and that our recruitment methods may have more general application.

Although lack of treatment with anticonvulsant medications does not necessarily imply inactive disease [12, 32], patient identification by antiepileptic drug prescriptions, can also include the mild and sometimes inactive cases often not generated in tertiary-based recruitment [20]. The HIC sample method only targets doctor-diagnosed 'screened' cases. With epilepsy prevalence expected to be less than $1 \%$ [33], it ensured we would generate a sufficient number of cases (necessary for future studies) to accurately estimate the demographic distribution of epilepsy and prevalence of seizure types and important epilepsy subtypes (e.g. idiopathic generalized epilepsy) rather than only the more heterogeneous diagnostic category 'epilepsy'.

When a single medical source is used, anticonvulsant prescriptions or general practitioners may be the most efficacious ascertainment source compared to other medical sources (hospital, specialist, EEG), with a study in Italy identifying most cases (82\%) equally from either anticonvulsant medications or family doctors compared to all other sources [34]. Anticonvulsant prescription recruitment is also an efficient method for yielding cases compared to door-to-door surveys. For example, in Zambia a survey conducted to generate cases for a similarly intended population-based disease registry required 55,000 individuals to be screened to yield around 800 cases [35]. While another house-to-house survey in Ecuador employed more than 275 people to screen a population of 
75,000 over 3 years and recruit about 1,200 lifetime cases [1]. In contrast, our study employed a 0.4 full-time equivalent (FTE) research assistant supervised by a 0.5 FTE research fellow for 1 year to screen a population of about 8,000 anticonvulsant prescription users over 6 months, yielding about 1,200 'active' cases from a source population of around half a million Tasmanians.

Given increasing time constraints on general practitioners, we did not want recruitment to be directly reliant on their case records or referral. In a study using repeat prescription data to ascertain cases over 6 months in nine general practices in Belfast, 1 in 4 cases had not attended their general practitioner or hospital outpatient department despite repeat prescriptions for anticonvulsants. Despite non-attendance for doctor consultation (but not for prescription uptake), half these patients had one or more seizures in the preceding 12 months, suggesting important active disease would have been unavailable for observation if recruitment had been reliant on direct doctor contact [36]. General practice has a service rather than research priority, it is not surprising then that it has been demonstrated to be less than an ideal direct source for data collection due to problems with validity and completeness [15]. Therefore, anticonvulsant prescription recruitment, although secondary to medical practitioner diagnosis and treatment, has the advantage that it does not rely on medical contact for denominator enumeration, invitation and patient participation.

Anticonvulsant medications are not exclusively prescribed for the treatment of epilepsy, i.e. they lack disease treatment specificity. They are also used to treat bipolar affective disorder, migraine, and chronic pain conditions. In Australia, doctors prescribing medications are not required to indicate what condition is being treated on a prescription. This means that our invited source population included disease groups other than our target population of treated epilepsy. Anticonvulsant treatment for conditions other than epilepsy in our study (44.4\%) was 1.5-4 times higher than that estimated in other prevalence studies involving prescription recruitment [3739]. Given these widely variable reported disease treatment proportions, rather than employing an empirical correction factor, as suggested [38], we excluded ineligible diseases by patient self-report whether anticonvulsants were prescribed for 'blank spells, seizures or epilepsy'. Coupled with our two mail-out invitation design, this will allow us to adjust for the effect of any disease-related non-response bias in subsequent prevalence study estimates using imputation methods. Imputation assumes a linear trend in prevalence with each subsequent contact, allowing the disease prevalence in non-responders to be extrapolated by linear regression [40, 41].

Although a number of studies have utilized anticonvulsant prescriptions to conduct epidemiological studies on epilepsy [20,37,42], there is limited comparable information related to case prescription sources. Considering only the first prescription identified in a 4-month period for patients receiving anticonvulsant drugs in New Zealand, $22.5 \%(333 / 1,479)$ of the patients received their prescriptions from a specialist rather than general practitioner sources, although specialist prescribing rates were almost twice as high for children [37], while a Dutch survey of patients with epilepsy regarding treatment and supervision found almost half (48\%) received their anticonvulsant drugs exclusively from a neurologist with a further $16 \%$ receiving them in combination with their GP [21]. However, both these studies suggest that the medical practitioner writing anticonvulsant drug prescriptions is most likely to also be responsible for disease supervision and follow-up. With 70.9\% of our Register cases receiving their anticonvulsant prescriptions exclusively from their general practitioner and $19.1 \%$ receiving them in part from a medical specialist in the preceding 12 months, it would suggest our cohort represents community-treated disease. Therefore, our subsequent prevalence estimates for seizures types, specific syndromes and co-morbid conditions associated with epilepsy should reflect this treatment group.

\section{Acknowledgements}

Wendyl D'Souza was supported from a Pfizer Alfred \& St Vincent's Hospital Electrophysiology Fellowship, St Vincent's Hospital Neuro-Epidemiology Fellowship and FRACP GSK Fellowship in Neurology. This project was generously supported by grants from The Booth Estate Launceston, Royal Hobart Hospital Research Foundation, GSK Neurology, Clifford Craig Medical Research Trust - North West Tasmania and Menzies Research Institute NHMRC Capacity Building Grant. The Centre for Public Health Research is supported by a programme Grant from the Health Research Council of New Zealand.

We would like to thank the Tasmanian Regional Divisions of General Practice, Specialist Physicians of Tasmania, The Epilepsy Association of Tasmania, the Pharmaceutical Guild of Tasmania, the Tasmanian Branch of the Pharmacist Society of Australia, and the Society of Hospital Pharmacists. We also thank our research assistants Nicole Mulcahy, Leanne Barnes and Charlotte McKercher for their considerable efforts in participant liaison, data processing and management. 


\section{References}

1 Placencia M, Suarez J, Crespo F, Sander JWAS, Shorvonl SD, Ellison RH, Cascante SM: A large-scale study of epilepsy in Ecuador: methodological aspects. Neuroepidemiology 1992;11:74-84.

$\checkmark 2$ Meneghini F, Rocca WA, Grigoletto F, Morgante L, Reggio A, Savettieri G, et al: Doorto-door prevalence survey of neurological diseases in a Sicilian population: background and methods. Neuroepidemiology 1991;10: 70-85.

-3 Osuntokun BO, Schoenberg BS, Nottidge VA, Adeuja A, Kale O, Adeyefa A, et al: Research protocol, measuring the prevalence of neurological disorders in developing countries. Results of a pilot study in Nigeria. Neuroepidemiology 1982;1:143-153.

$\checkmark 4$ Schoenberg BS: Clinical neuroepidemiology in developing countries: Neurology with few neurologists. Neuroepidemiology 1982;1: 137-142.

5 Sander JWAS, Shorvon SD: Incidence and prevalence studies in epilepsy and their methodological problems: a review. J Neurol Neurosurg Psychiatry 1987;50:829-839.

6 Australian Bureau of Statistics: Population by Age and Sex, Australian States and Territories. Canberra, Australian Bureau of Statistics, June 2003, Rep. No.: Cat. No. 3201.0

7 Jones G, Ding CH, Hynes KL, Ma D, Glisson M, Cicuttini FM: Knee articular cartilage development in children: a longitudinal study of the effect of gender, growth, Tanner stage and physical activity. Pediatr Res 2003, 54:230-236.

8 Department of Health \& Aged Care: The Australian Health Care System: An Outline. Canberra, Department of Health \& Aged Care, Sept 2000, Rep. No.: Publ Approval No. 2545.

9 Edmonds DJ, Dumbrell DM, Primrose JG, McManus P, Birkett DJ, Demirian V: Development of an Australian Drug Utilisation Database. Pharmacoeconomics 1993;3:427432.

10 Robertson J, Fryer J, O’Connell DL, Smith AJ, Henry DA: Personal formularies: an index of prescribing quality? Eur J Clin Pharmacol 2001;57:333-341.

11 Trewin D: Information Paper: Census of Population and Housing Socio-Economic Indexes for Areas (SEIFA), 2001; ABS Catalogue No. 2039.0. ISBN 0-642-47936-4.

12 Oun A, Haldre S, Magi M: Prevalence of adult epilepsy in Estonia. Epilepsy Res 2003; 52:233-242.
13 Keränen T, Riekkinen PJ, Sillanpää M: Incidence and prevalence of epilepsy in adults in Eastern Finland. Epilepsia 1989;30:413421.

14 Wright J, Pickard N, Whitfield A, Hakin N: A population-based study of the prevalence, clinical characteristics and effect of ethnicity in epilepsy. Seizure 2000;9:309-313.

15 MacDonald BK, Cockerell OC, Sander JWAS, Shorvon SD: The incidence and lifetime prevalence of neurological disorders in a prospective community-based study in the UK. Brain 2000;123:665-676.

16 Wallace H, Shorvon SD, Tallis R: Age-spe cific incidence and prevalence rates of treated epilepsy in an unselected population of $2,052,922$ and age-specific fertility rates of women with epilepsy. Lancet 1998;352:1970 1973.

17 Goodridge DMG, Shorvon SD: Epileptic seizures in a population of 6,000. Br Med J 1983; 287:641-645.

18 Groves RM, Dillman DA, Eltinge JL, Little RJA: Survey Nonresponse. New York, Wiley, 2001.

19 Cockerell OC, Eckle I, Goodridge DMG, Sander JWAS, Shorvon SD: Epilepsy in a population of 6,000 re-examined: secular trends in first attendance rates, prevalence, and prognosis. J Neurol Neurosurg Psychiatry 1995;58:570-576.

20 Giuliani G, Terziani S, Senigaglia AR, Luccioni G, Foschi N, Maffer C: Epilepsy in an Italian community as assessed by a survey for prescriptions of antiepileptic drugs: epidemiology and patterns of care. Acta Neurol Scand 1992;85:23-31.

21 Rutgers MJ: Epilepsy in general practice: the Dutch situation. Epilepsia 1986;27:734-738.

22 Wang WZ, Wu JZ, Wang DS, Dai XY, Yang $B$, Wang TP, et al: The prevalence and treatment gap in epilpesy in China. Neurology 2003;60:1544-1545.

23 Coleman R, Loppy L, Walraven G: The treatment gap and primary health care for people with epilepsy in rural Gambia. Bull World Health Organ 2002;80:378-383.

24 Bharucha NE, Bharucha EP, Bharucha AE, Bhise AV, Schoenberg BS: Prevalence of epilepsy in the Parsi community of Bombay. Epilepsia 1988;29:111-115.

25 Olafsson E, Hauser WA: Prevalence of epilepsy in rural Iceland: a population-based study. Epilepsia 1999;40:1529-1534.

26 Beran RB, Hall L, Pesch A, Ho P, Lam S, Leung P-Y, et al: Population prevalence of epilepsy in Sydney, Australia. Neuroepidemiology 1982;1:201-208.

27 Zeilinski JJ: Epileptics not in treatment. Epilepsia 1974;15:203-210.
28 Haerer AF, Anderson DW, Schoenberg BS: Prevalence and clinical features of epilepsy in a biracial United States population. Epilepsia 1986;27:66-75.

29 Forsgren L: Prevalence of epilepsy in adults in Northern Sweden. Epilepsia 1992;33:450458.

30 Da Mota Gomes M, Zeitoune RG, Kropf LAL, van Beeck EdS: A house-to-house survey of epileptic seizures in an urban community of Rio de Janeiro, Brazil. Arq Neuropsiquiatr 2002;60(3-B):708-711.

-31 Rocca WA, Savettieri G, Anderson DW, Meneghini F, Grigoletto F, Morgante L, et al: Door-to-door prevalence survey of epilepsy in three Sicilian Municipalities. Neuroepidemiology 2001;20:237-241.

32 White PT, Buckley EG: The management of epilepsy - an audit of two practices. Health Bull (Edinb) 1981;39:82-88.

33 Sander JWAS, Shorvon SD: Epidemiology of the epilepsies. J Neurol Neurosurg Psychiatry 1996;61:433-443.

34 Maremmani C, Rossi G, Bonuccelli U, Murri L: Descriptive epidemiologic study of epilepsy syndromes in a district of Northwest Tuscany, Italy. Epilepsia 1991;32:294-298.

35 Birbeck GL, Kalichi EMN: Epilepsy prevalence in rural Zambia: a door-to-door survey. Trop Med Int Health 2004;9:92-95.

36 McCluggage JR, Ramsey HC, Irwin WG, Dowds MF: Anticonvulsant therapy in a general practice population in Northern Ireland. J R Coll Gen Pract 1986;34:24-31.

37 Lambie DG, Johnson RH, Stanaway L: Prescribing patterns for epilepsy. NZ Med J 1981;94:15-19.

38 De la Court A, Breteler MMB, Meinardi H, Hauser WA, Hofman A: Prevalence of epilepsy in the elderly. The Rotterdam Study. Epilepsia 1996;37:141-147.

39 Beghi E, Monticelli ML, Monza C, Sessa A, Zarrelli MM: Antiepileptic drugs as 'tracers' of disease. A calculation of the prevalence of epilepsy through an analysis of drug consumption. Neuroepidemiology 1991;10:3341.

40 Drane JW: Imputing nonresponses to mailback questionnaires. Am J Epidemiol 1991; 134:908-912.

41 Drane JW, Richter D, Stoskopf C: Improved imputation of non-responses to mailback questionnaires. Stat Med 1993;12:283-288.

-42 Lammers MW, Hekster YA, Keyser A, Meinardi H, Renier WO, Herings RMC: Use of antiepileptic drugs in a community-dwelling Dutch population. Neurology 1996;46: 62-67. 